\title{
Labour Migration and Shadow Prices
}

\author{
HENRY J. BRUTON*
}

\begin{abstract}
The effect of migration and home remittances on the shadow prices of labour and foreign exchange is analysed here, taking into consideration changes in their social marginal productivities. It is argued that appreciation of currency, due to large capital inflows and not to increased productivity, results in a misallocation of resources, and, therefore, there is an urgent need for a proper analysis to determine the optimal level of emigrants.
\end{abstract}

\section{INTRODUCTION}

Exchange rate and wage rate policy have long been a strategic aspect of the trade and industrialization policies of developing countries. Theoretical literature has usually approached these issues by using shadow prices of foreign exchange and of labour to determine the appropriate choice of product to produce and of technique to use. Shadow prices are worrisome enough conceptually, and for practical purposes they are even more difficult to define and to employ in any relevant way. Still the notion of a shadow price of foreign exchange and of labour is obviously important, and further study of the question, especially from a policy standpoint, is useful.

In this paper I discuss these issues in a situation that, during the past several years, has become increasingly relevant to a number of countries, including Pakistan. The context is that of a country from which a sizeable number of workers migrate to work abroad. From the foreign country they send money (foreign exchange) back to their home country. Wages in the country attracting workers are much higher, of course, than in the country losing the workers. How does this situation affect the shadow price of labour and of foreign exchange in the country from which labour migrates?

International migration has again become a significant phenomenon in many parts of the world. A very rough adding up of available data suggests that possibly 15-20. million people are working (or seeking work) in countries that they do not call home. The migrations affect some countries more than others, but an increasing

*The author is Regional Representative of the Ford Foundation for Middle East and North Africa. 
number of countries are being affected in one way or another. In some small countries now (mid-1980), nationals of the country make up less than one-half of the labour force of the country. In Qatar and Kuwait non-nationals make up between 70 and 80 percent of the work force. In the much larger countries of Saudi Arabia and Libya, non-nationals make up over 40 percent of the total labour force. ${ }^{1}$

In the United States, along the border with Mexico the labour force is from 50 to 75 percent Mexican. In some occupational categories in Western European countries, almost all the engaged workers are "temporary" migrants [2] .

From the other side, a given country may have a sizeable proportion of its labour force abroad, and an even larger proportion of those possessing certain skill categories may be working abroad. For example, the Birks and Sinclair data show that in 1975 some 150,000 Jordanians worked abroad out of a total work force of 533,000 . Some estimates place 10 percent of Egypt's 12 million-person labour force abroad. Data on Egypt are difficult to appraise, and other estimates are as low as five percent. Very careful estimates suggest that as many as 50 percent of Egypt's experienced construction workers were working abroad in 1977-78. Recently, Egyptians have migrated to Jordan to replace Jordanians who have migrated to Saudi Arabia who in turn have migrated to London and Los Angeles.

These brief examples are meant to show that the migration phenomenon has become of importance in the economic development effort of many countries. In the past several years a substantial literature has appeared that seeks to measure the extent and to analyze the consequences of this large movement of labour. The most useful general review of these issues (with specific attention to the Middle East) is the Birks and Sinclair study [1]. That study includes a useful bibliography.

The issue associated with these large-scale migrations accompanied by equally large-scale remittances is to be distinguished from the so-called brain-drain problem. In the brain-drain problem, attention is focused on the (more or less permanent) migration of highly skilled professionals who perform key functions in the economy. Such people have often received their training at the cost of their native land and rarely remit foreign exchange in sufficient amounts to matter very much. The largescale migrations considered here create a different sort of problem. As will be discussed below, factor supplies and prices are changed in both the sending and receiving countries, at least temporarily, so that socially profitable investment projects are affected, export potential is modified, and so on. These migrant workers also usually plan to return after some period. In certain instances, the brain-drain phenomenon has reached proportions that do affect factor prices. For example, it has been suggested that doctors of Indian nationality are so numerous in Great Britain that they decidedly affect medical costs and choice of educational

${ }^{1}$ These data are at best approximate. The most accurate estimates are for 1975. Birks and Sinclair [1] have a useful collection of tables on various characteristics of Middle Eas migration. The data given here were taken from these tables. programmes in the country. One might indeed make the case that if all Indian doctors were to return to India from all countries, the British (and other nationalities) would begin to travel to India for serious, non-emergency medical treatments. With the decline in the relative cost of air travel, medical service could then become a "traded good".

It is also to be noted that the discussion here does not apply to politically induced movements of peoples. Evidently, for example, the migrations or attempted migrations now taking place in parts of Southeast Asia are very different in cause and consequence from the kind of thing considered in this paper.

\section{II}

The task now is to develop a way of organizing our thinking about the consequences of these large-scale migrations of labour.

The simplest argument to make is the following. It is assumed that the country supplying the labour has a surplus of labour in the sense that the marginal social product of labour is zero due to the absence of a sufficient quantity of complementary inputs. It is further assumed that foreign exchange is the immediate constraint to increased output and employment in this country. In this event, the labour-supplying country is exporting a product, labour services, which has a marginal social product of zero and receives in return a product, foreign exchange, which has a very high marginal social product. Evidently, this simple story leads to the conclusion that labour migration increases social welfare as long as these assumptions apply. At some rate (possibly very low) of labour migration, however, the assumptions no longer apply. Labour's marginal social product will become positive at home and the productivity of additional units of foreign exchange begins to fall. When this point is reached, the analytical and practical problems become more interesting. The objective now is to explore this situation.

The social productivity (to the supplying country) of a migrant worker is equal to the contribution to the social welfare made by the foreign exchange that the worker sends back to the home country. In an extreme case, suppose all workers migrate, and there is no domestic production at all. The marginal social product of migrant labour would then equal that of one (e.g.) dollar's worth of increased imports of consumer goods. Although all workers never migrate (except possibly from a particular region) this extreme case is perhaps not as unrealistic as it might first appear, and it helps to illuminate an essential part of the problem.

To illuminate this "essential part" further, consider the consequences of the large number of workers who migrated to Western Europe in the 1960s and early 1970 s from northern Africa, Spain, Portugal, Turkey, Yugoslavia, and elsewhere. The movement of these workers into the Western European economies had the effect of preventing these latter economies from experiencing skyrocketing labour costs. Had the immigrant workers not been available to Western Europe, a wide range of 
activities located there would simply not have remained competitive in world markets. So the migrations improved the competitive position of Western European countries in those activities that used unskilled and less skilled labour most intensively. It improved the European countries' competitive position in those activities in which labour-supplying countries could be expected to be most competitive. The process therefore dampened the opportunities for the evolution of new investment projects in the labour-supplying countries. At the same time that this was happening, the flow of foreign exchange, as an unrequited cash transfer, to the labour-supplying country increased the value of that country's currency relative to the value of foreign exchange and thereby made exporting more difficult. This development adds to the difficulty of identifying new investment projects.

What happened in the European case is very much akin to the case where all workers migrate and send funds home to maintain a purely consumption economy. The migration of many workers into the Western European economies made it possible for them to continue production in areas where, in the absence of the migration, they would have been unable to compete. To a considerable extent, these are the same or similar activities that could have evolved in the labour-supplying country had the labour not migrated. The increased availability of the foreign exchange remitted creates further difficulties for the labour-supplying country to compete with new activities as the price of domestic currency rises relative to foreign currency. In the case where all workers migrate, no new activities evolve in the "home country" (the labour-supplying country) because there was no labour there. In the more realistic case, the foreign exchange remittances do not facilitate the appearance of new activities, new employment opportunities, because of the difficulties created in identifying and implementing new projects in the face of the strengthened competition abroad, the less favourable (for exports) exchange rate, and the less favourable labour market. The result is that the remitted funds go heavily for imported consumer goods rather than for investment [3].

The Western European case is the most evident example of the past, but there are others. The border between the United States and Mexico offers another example. Mexican workers cross the border into the United States in large numbers (often illegally), and thereby make many activities - especially citrus farming, strawberry raising, milk-cow and cattle ranching - profitable in the United States. None of these is profitable without the Mexican labour. These same activities would constitute excellent export activities in Mexico were Mexican labour not to migrate and, by not migrating, force these activities to cease to function in the United States. The consequence of all this has been that new employment-creating activities in Mexico along the border with the United States are severely penalized, and there is little gain to compensate for the penalty. ${ }^{2}$ ${ }^{2}$ See Michael Piore [6] for a different and more detailed analysis of the Mexican emigra-
tion issue
The most recent area where large-scale migration of workers has become of great importance is the Middle East. The large increase in the price of oil in 1973-74 set off the enormous investment programme in the foreign-exchangesurplus, labour-short economies of the Middle East and Libya. As already noted, labour was attracted from surrounding and distant countries in large numbers by evident employment opportunities and wages five to 20 times higher than those paid in the labour-supplying countries.

The events in Egypt may be used to illustrate the general arguments referred to above. For many years before the oil price increase, Egypt supplied school teachers to the Persian Gulf countries. The teachers were in plentiful supply in Egypt and were government employees, and any shortage in Egypt could be quickly and easily replaced. In this case, it seems fairly clear that the marginal social product of the workers who migrated was very low in Egypt while the foreign exchange they sent or brought home had a very high marginal product. The arrangement was surely socially as well as individually profitable.

Since about 1975, the number of workers migrating from Egypt has increased enormously. It was noted in Section I that possibly $1.2-1.4$ million Egyptians worked abroad now compared to 400,000 in 1975 [5]. Included are professionals of all kinds - doctors, lawyers, nurses, engineers, architects, teachers, etc. - but bluecollar workers and the unskilled construction workers in particular have migrated. Remittances of foreign exchange by these workers now amount to over two billion dollars by official estimates, and the actual figure is doubtless much larger. The Gross Domestic Product in Egypt being about the equivalent of 16-17 billion US dollars, the remittances are thus 12.5 percent or more of the GDP.

The Egyptian story is repeated on a smaller or larger scale in a variety of other countries in the Middle East and South Asia.

\section{III}

In this part, an effort is made to put the preceding points in a more formal way. In the diagram, the annual quantity of labour services provided by the workers working abroad is measured on the horizontal axis. On the vertical axis is measured the domestic (i.e. of the labour-supplying country) social marginal product, SMP, of two kinds of labour: (i) that which is working abroad (MSP-LA) and (ii) that which is working (or is unemployed) at home (MSP-LD). The domestic SMP of the workers abroad is, as noted, equal to the increment in social welfare produced by an additional unit of foreign exchange remitted by the worker. The SMP of domestic labour is shown by the line $\mathrm{OAL}_{d}$ and that of migrated labour by $\mathrm{PA}^{\prime} \mathrm{L}_{\mathrm{a}}$. The interval OA shows the amount of labour that can go abroad without penalizing the economy by creating labour shortages of any kind. As labour services in excess of OA migrate, the domestic SMP of labour begins to rise. In different words, an amount of labour service equal to $\mathrm{OA}$ is redundant in the economy and can migrate 
with no sacrifice to domestic output. Labour migration in excess of OA means that the economy sacrifices some social product as a consequence of the migration of the labour service.

The line $\mathrm{PA}^{\prime} \mathrm{L}_{\mathrm{a}}$ shows the SMP to the labour-supplying country of an additional unit of foreign exchange remitted by its nationals who are working abroad.

The interval $\mathrm{PA}^{\prime}(=\mathrm{OA})$ identifies the amount of labour services that can go abroad and send home foreign exchange that represents an unqualified gain to the home country. From $\mathrm{A}^{\prime}$, the SMP of foreign exchange falls, i.e. the domestic SMP of nationals working abroad begins to fall. The diagram shows that if labour in excess of OL migrates, the country suffers reduced social welfare.

Consider first why the curve $\mathrm{PA}^{\prime} \mathrm{L}_{\mathrm{a}}$ has the shape that it has. The horizontal interval PA' $^{\prime}$ represents the quantity of labour which can leave the country and impose no costs on the domestic economy. All the foreign exchange remittances, therefore, represent a gain to the domestic economy. Similarly, OA identifies the quantity of labour that can migrate without imposing any costs on the economy from a labour "shortage".

Beyond $\mathrm{A}^{\prime}$, the $\mathrm{PA}^{\prime} \mathrm{L}_{\mathrm{a}}$ curve falls for a variety of reasons. The inflow of worker-remittances begins to create problems that offset some of the advantages of the additional foreign exchange. What exactly are these problems? Some appear quite specific and others quite nebulous. As the receipts of foreign exchange rise, difficulties increase in insuring their optimal use. The workers who go abroad increase their earnings by a very substantial amount. Usually the remittances are untaxed. Income distribution is therefore necessarily affected. In addition, depending on foreign exchange regulations, the remittances often make possible increased access to imports. Hence, inequality is increased, and may take the form of inequality in access to imported consumer goods. Both developments may mean that the social welfare associated with the added foreign exchange is reduced. Even if the increased supply of foreign exchange accrues directly to the Central Bank, difficulties of managing it will increase, and opportunities for misallocation become more plentiful. In particular, the management of investment projects heavily using foreign exchange is more demanding than of those in which familiar domestic resources are the primary input. The latter investments also impose fewer social and cultural adjustments on the population, and such adjustments almost inevitably reduce the social welfare associated with development. Also, the problem of maintaining appropriate control of the domestic money supply may be made more complex. All of these considerations enter in more or less degree to affect the SMP of the foreign exchange that is remitted. The most specific reason for the fall in the SMP of the foreign exchange sent home from abroad is simply that it has a declining quantity (after OA) of labour available to use it. This consequence bears on the question of the exchange rate. It is discussed below. 
Consider now the shape of $\mathrm{OAL}_{\mathrm{d}}$. The interval OA may measure the quantity of unemployed or under-employed labour. Departure of this labour, by definition, does not reduce the output of the economy. Beyond A, however, labour's productivity at home becomes positive, and migration must begin to include workers now contributing to output. As increasing amounts of labour services migrate, the domestic supply of labour is further reduced and therefore the output sacrificed by the migration continues to rise. The problem is exacerbated if the specific skill that migrates is especially difficult to replace. If a first-rate plumber migrates, and is replaced by a second- or third-rate plumber - one who works more slowly, whose work must be compensated for by the carpenters - then, of course, the shape of $\mathrm{AL}_{\mathrm{d}}$ is much steeper than if the migrants were the unskilled, easily substitutable workers. One might conceive of a family of curves from A, the shape of which depends on the composition of skills that migrate. All curves would turn from the horizontal toward the northeast at some quantity of labour service abroad. The most concrete reason for the rising $L_{d}$ curve is that more foreign exchange becomes available domestically as the quantity of labour services abroad rises. The increased supply of foreign exchange per domestic worker may be expected to raise the productivity of workers remaining at home.

All these considerations bear on the question of the appropriate wage and the appropriate exchange rate.

\section{IV}

We seek now to say something specific about the shadow price of foreign exchange and of labour in the context of the preceding argument.

The SMP to the domestic economy of the workers abroad is the productivity of the foreign exchange that the worker remits. We have argued that this productivity falls as the amount of labour services abroad increases, i.e. as the amount of foreign exchange remitted increases. The wage paid to the migrant worker, however, is presumably based on the productivity in the labour-importing country. An evident conflict appears between the profitability of migration to the individual and corresponding profitability to the domestic economy - even in the case where the worker remits all or virtually all his earnings. Similarly, the abundance of foreign exchange tends to push down the exchange rate (i.e. lowers the price of foreign currency relative to domestic currency) at the time the economy becomes less equipped to employ it. For the domestic country to offer wage rates that will keep workers at home will result in a misallocation, including unemployment. To appreciate the domestic currency would also impose a misallocation because the strength of the domestic currency has arisen not from the productivity of the migrated workers in the host country. The policy objective is to aim at OL (in the diagram), labour services abroad, given a certain rate of remittances.
Evidently, differential income taxes on foreign and domestic earnings can, at least conceptually, be designed that would penalize those working abroad to the extent that, no matter what the differential earnings, only OL labour service would go abroad. At the present time, a large part of earnings abroad escapes taxation, and designing and administrating a tax scheme that would achieve the appropriate discouragement to migrating is a major task. The frequently heard proposal of arranging for the host government to tax the workers and repatriate the tax collections would have a similar impact. The host government, however, does not have the same objective as does the home government, and, of course, all workers do not migrate to the same host country. Dependence on the host government would, therefore, probably not be a practical solution. A differential income tax is justified on the grounds that the labour migration imposes certain external diseconomies on the country which should in principle be compensated for by the person inflicting the diseconomies. The tax would be paid in foreign exchange, and would thereby probably result (depending on the foreign exchange regulations of the country) in a large part of the remittances being acquired by the government itself. This has certain advantages of both control of its use and, more importantly, its impact on the exchange rate. The objective of the tax is to equate the domestic SMP of the migrated worker with the after-differential-tax wage the worker receives. Evidently, the tax would have to be set on the basis of actual wages paid to the migrant workers. To do this exactly imposes major administrative problems, but to do it approximately should be relatively simple.

What then in this situation is the shadow exchange rate? This is a much more difficult question. The additional foreign exchange might provide an opportunity to relax trade controls, quotas, review tariffs, etc. which often results in a spurt of imports. The added foreign exchange would enable the country to survive that shortrun problem. If the remittances continue, however, the exchange rate will necessarily become an issue because, as noted, the remittances do not arise out of the productivity of the labour-supplying, remittance-importing country. The main problem is that of investment-project identification and selection and productivity growth in this country, and the consequent adverse effect on saving rates. If the price of domestic currency is kept low as the foreign exchange receipts rise, then presumably reserves of foreign exchange will become undesirably large. Direct subsidies to exports are difficult to design in the appropriate way and to administer once designed. Also it is often cumbersome to solve the purely financing side of a widespread subsidy.

Dual exchange rates, explicitly maintained, also cause administrative problems. One approach that has some of the effects of a dual exchange rate is the following: the government withdraws a certain quantity of foreign exchange from the foreign exchange market. This is to be used for a variety of projects aimed at raising the 
general productivity of the economy, the most obvious of which are often infrastructure projects. Improved transportation and communication especially should make new investments more productive in many countries. Housing is another candidate for expenditure from this "isolated" foreign exchange. The withdrawal of the foreign exchange used for these purposes would, of course, mean less foreign exchange flowing into the general foreign exchange pool which is assumed to act on the exchange rate. Foreign currency would therefore have a higher value than it would have were all the foreign exchange put into the general pool. Thus investment projects drawing from the pool would be paying a price for foreign exchange that measured more accurately the productivity of the general economy. This situation would make exporting more appealing and, more importantly, emit the signals appropriate to reflecting the capacity of the economy to use foreign exchange.

There are doubtless other ways to accomplish the desired objectives. A general point in conclusion: the development objective has so frequently been constrained (or thought to be constrained) by foreign exchange that a situation where that is not the case creates some problems that have not been well explored. It seems especially important to appreciate that the SMP of foreign exchange does fall as its availability increases. The fact that migrating workers remit foreign exchange does not automatically mean that their migration is socially profitable. It then becomes necessary to try to understand the social productivity lost to the country by the migration and that gained by the remittance. When that is understood, then the policy objective is to design the means by which these SMPs will be reflected in earnings and in the exchange rate. To make a contribution to this point has been the purpose of this paper.

\section{REFERENCES}

1. Birks, J. S., and C. A. Sinclair. International Migration and Development in the Arab Region. Geneva: International Labour Office. 1980.

2. Böhning, W. R. "Some Thoughts on Emigration From the Mediterranean Basin" International Labour Review. March 1975.

3. Granier, R., and J. P. Marciano. "The Earnings of Immigrant Workers in France" International Labour Review. February 1975.

4. Middle East Economic Digest. Various recent issues.

5. Mabro, Robert E. The Egyptian Economy 1952-1972. London: Oxford University Press. 1974.

6. Piore, Michael J. Birds of Passage: Migrant Labour and Industrial Societies. Cambridge: Cambridge University Press. 1980.

\section{Notes and Comments}

\section{"Shadow Prices for Pakistan: An Assessment of Alternative Estimates" - A Reply}

\author{
JOHN WEISS*
}

Ms. Tsakok [1] has done a useful job in summarising and commenting on the various estimates of shadow prices which appeared in the symposium on shadow pricing in Pakistan, published in the Summer 1979 issue of this Review. However, her discussion of my paper in the symposium [3] ${ }^{1}$ is misleading regarding a number of points of detail, and, more seriously, obscures the general thrust of the argument. Considering the detailed points first, Ms. Tsakok is concerned with a comparison of 列 the values of the key shadow prices given in the different studies as welles. JW explanations for the variations between the different estimates. However, Jw discusses not the estimation of a set of shadow prices for Pakistan, but the broader question of the implications of the use of an income-weighting system, described conventionally as 'social' analysis, in project appraisal. The shadow prices attributed to my work in Table 1 of Ms. Tsakok's paper [1] are not in fact contained in JW, but are taken from an earlier mimeographed paper written in 1977 . These shadow prices are preliminary estimates, which are not used in my more detailed study on costbenefit analysis in Pakistan [2]. ${ }^{2}$ Furthermore, it is strange to find these estimates cited, since they conflict with the analysis of JW, which is the paper under review.

Firstly, Ms. Tsakok gives my estimate of the Standard Conversion Factor (SCF) , SCF is used in the discussion of $v$, the value of public income as 0.91. In JW, the SCF is used in the discussion relative to average private consumption. There, the SCF is taken to be the same figure as that attributed to Squire-Little-Durdag by Ms. Tsakok Ms. Tsakok refers to my estimate of the Consumption Conversion Factor (CCF) of 0.98. However, JW contains no reference to a CCF. There, in the analysis of the SCF is used as a proxy for the CCF. Thirdly, Ms. Tsakok gives my estimate of $v$ as within a range between 1.3 and 2.8 . However, much of the analysis of JW is concerned with the difficulty of estimating a meaningful value for $v$. In particular,

The author is associated with the Project Planning Centre of the University of Bradford, is on leave from the Centre, working as a Consultant to the Bradford (England). Cur

Ts. Tsakok, this paper will be referred to as JW.

${ }_{2}^{1}$ Henceforth, following the terminology of Ms. Tsakok, this paper will be 
its sensitivity to the choice of the Consumption Rate of Interest (CRI) is stressed. Since one of the conclusions of JW is that the Squire-van der Tak weighting system is difficult to apply because of the problem of estimating $\mathrm{v}$, and since a very wide range of possible values of $v$ is identified, it is odd that such a narrow range should be referred to by Ms. Tsakok. Fourthly, Ms. Tsakok attributes to my analysis a weight of 1.0 for consumers at the Critical Consumption Level (CCL). This follows since the CCL is defined by the equality

$$
\frac{\mathrm{di}}{\mathrm{v}}=\mathrm{B}
$$

where di is the weight given to consumers at the CCL in relation to average consumers, and B is the CCF. As my earlier paper used a value of 0.98 (rounded to 1.0) for the $\mathrm{CCF}, \frac{\mathrm{di}}{\mathrm{v}}$ at the CCL must equal 1.0. However, this approach again conflicts with the argument of JW since it follows the weighting system of Squire and van der Tak, whilst JW suggests an alternative approach to weighting which does not involve the use of the parameter v. Finally, with reference to my treatment of the opportunity cost of public investment, q, Ms. Tsakok points out rightly that my discussion of this parameter in JW is very brief. However, a more detailed analysis is given in the study on the application of the UNIDO methodology [2] referred to above, although both the practical and conceptual problems regarding $\mathrm{q}$, mentioned by Ms. Tsakok, are not solved satisfactorily.

The general thrust of the argument of JW is to question the usefulness of the extension of cost-benefit appraisals into the field of 'social' analysis. JW argues that there are major difficulties in applying an income-weighting analysis, both in estimating actual income changes created by a project and in identifying a relevant set of weights to revalue these income flows. It suggests that decision-taking on projects on its own is unlikely to be an effective policy instrument in achieving significant income redistribution. Ms. Tsakok, by carrying out an overall survey of the various shadow price estimates, does not distinguish clearly enough between problems related to 'social' analysis and those related to 'economic' or efficiency analysis. It is clearly correct to point to the inadequacy of some of the calculations in the symposium papers due to poor data, and to stress the need for frequent revisions of estimates as more data become available. However, JW stresses the particular problems for the application of social analysis, resulting from the intrinsically subjective nature of key parameters such as the CRI and v. Even with an improved set of basic data these problems will remain. Furthermore, the application of social analysis requires considerably more additional information on specific projects, if the income changes created by projects are to be identified in a meaningful way.

Ms. Tsakok ends her comments with the suggestion that what is needed is an in-depth study of the usefulness of shadow pricing analysis as an aid to decision- taking. It is important to remember that the literature on cost-benefit analysis for investment appraisal in developing countries considered originally that only a few major adjustments to market prices would be required, relating chiefly to the discount rate, the exchange rate for foreign currency, the wage for unskilled labour, and the prices of some internationally traded commodities. In recent years, the development of the so-called comprehensive methods of cost-benefit appraisal has meant that a complex theoretical structure has been erected whose application, in principle, involves a comprehensive set of detailed shadow price estimates. The papers in the symposium illustrate many of the problems involved in producing such a set of estimates, and Ms. Tsakok is correct to stress the limitations of those given for Pakistan. However, there is considerable evidence from a number of countries that decision-taking on projects can be improved by introducing relatively crude adjustments to the market prices of a relatively small number of key parameters. The position implicit in JW is that whilst there may be major difficulties in introducing a detailed 'social' analysis of projects, a relatively simple form of 'economic' or efficiency analysis can be a useful aid to decision-taking.

It is not a question of whether the relatively simple shadow prices used in such an analysis are wholly accurate reflexions of the full effects on the economy of using inputs or producing outputs on a project. The question is whether they capture these effects more accurately than do prevailing market prices. In many economies, market prices are such inadequate measures of full costs and benefits, however these are defined, that this is likely to be the case. However, this relatively simple type of cost-benefit appraisal is a very long way removed from the application of detailed and comprehensive sets of shadow prices. As Ms. Tsakok suggests, for many economies the practical effects of this comprehensive approach may remain small because of the problems involved in the estimation of the necessary parameters.

\section{REFERENCES}

1. Tsakok, Isabelle. "Shadow Prices for Pakistan: An Assessment of Alternative Estimates". Pakistan Development Review. Vol. XVIII, No. 3. Autumn 1979. pp. 253-263.

2. Weiss, John. Practical Appraisal of Industrial Projects: Application of Social Cost Benefit Analysis in Pakistan. New York: UNIDO. 1980 [Sale No. E79 II B.5] .

3. Weiss, John. "Project Selection and Equity Objective: The Use of Social Analysis”. Pakistan Development Review. Vol. XVIII, No. 2. Summer 1979. pp. 147-163. 